\title{
Errata
}

\section{Computational Optimization and Applications Volume 34, Number 2, June 2006}

Published online: 14 August 2006

The publisher regrets that many of the dates were incorrect in the June issue of Computational Optimization and Applications, Volume 34, Number 2, June 2006, which contained the following articles:

Interior-Point Algorithms, Penalty Methods and Equilibrium Problems by Hande $Y$. Benson, Arun Sen, David F. Shanno and Robert J. Vanderbei (pp. 155-182; DOI: 10.1007/s10589-005-3908-8)

A New Path-Following Algorithm for Nonlinear $\mathrm{P}^{*}$ Complementarity Problems by $Y$. B. Zhao and D. Li (pp. 183-214; DOI: 10.1007/s10589-005-3905-y)

Convergence Rate of The Trust Region Method for Nonlinear Equations Under Local Error Bound Condition by Jinyan Fan (pp. 215-227 ; DOI: 10.1007/s10589-005-3078-8)

Univariate Global Optimization with Multiextremal Non-Differentiable Constraints Without Penalty Functions by Yaroslav D. Sergeyev (pp. 229-248 ; DOI: 10.1007/s10589005-3906-x)

A Novel Filled Function Method and Quasi-Filled Function Method for Global Optimization by Z. Y. Wu, H. W. J. Lee, L. S. Zhang and X. M. Yang (pp. 249-272 ; DOI: $10.1007 / \mathrm{s} 10589-005-3077-9)$

A Dual-Objective Evolutionary Algorithm for Rules Extraction in Data Mining by K. C. Tan, Q. Yu and J. H. Ang (pp. 273-294 ; DOI: 10.1007/s10589-005-3907-9)

The top line of the credit line for every article should have read as "Computational Optimization and Applications, 34, the page range of the article, 2006".

The copyright year for all of the articles with the exception of the article by Wu et al. should have read as 2006 and not 2005. 